\title{
Is Healthy Eating Healthy for the Environment? Barilla Center for Food and Nutrition Double Food Pyramid
}

\author{
Luca Ruini ${ }^{1, *}$, Roberto Ciati ${ }^{1}$, Carlo Alberto Pratesi ${ }^{2}$, Ludovica Principato ${ }^{3}$, \\ Massimo Marino ${ }^{4}$, and Sonia Pignatelli ${ }^{4}$ \\ ${ }^{1}$ Barilla G.e R. Fratelli S.p.A., Parma, Italy \\ \{luca.ruini, roberto.ciati\}@barilla.com \\ ${ }^{2}$ Roma Tre University, Rome, Italy \\ pratesi@uniroma3.it \\ ${ }^{3}$ La Sapienza University, Rome, Italy \\ ludovica.principato@uniroma1.it \\ ${ }^{4}$.StudioLCE, Turin, Italy \\ \{marino, pignatelli\}astudiolce.it
}

\begin{abstract}
Barilla Center for Food and Nutrition decided to repropose an updated food pyramid, involving global warming and impacts of food on the environment. It has been made a reclassification of foods that together with their positive impacts on health also included their environmental impacts. These values were overlapped in descending order to obtain an upside-down pyramid that reproposes the same succession of foods. The new "Double Pyramid" shows that foods with higher recommended consumption levels are also those with lower environmental impact, and foods with lower recommended consumption levels are those with higher environmental impact.

Two daily menu were analysed: both balanced from a nutritional point of view, but in the first one the protein is of plant origin, while in the second one it is mainly of animal origin. Vegetarian menu has an environmental impact that is two and a half times lower than the animal protein-based one.
\end{abstract}

Keywords: Nutrition, ecological footprint, carbon footprint, water footprint.

\section{Introduction}

It is generally known that proper nutrition is an essential condition to health. This is a natural law that, however, has not received due attention in the last few decades. Indeed, the growing impact of disorders related to overeating serves as testimony of this last observation. Common disorders are: obesity, diabetes and cardiovascular pathologies - in people of all ages, including the younger portion of the population (Must et al., 1999; Burton et al., 1985).

In the 1970s, American physiologist Ancel Keys explained to the world the diet he dubbed "Mediterranean" based on balanced consumption of natural foods (olive oil, fruit, grains, legumes, etc.), thanks to which death rates from heart disease were

\footnotetext{
* Corresponding author.
} 
shown to be lower than with saturated fat-rich diets typical of Northern Europe. In 1992, the US Department of Agriculture developed and released the first Food Pyramid which concisely and efficaciously explained how to adopt a nutritionallybalanced diet.

Aimed at commencing nutritional education, at the start of the 1990s the US Department of Agriculture elaborated and disseminated the first "food pyramid", based on the scientific studies of Ancel Keys. This structure provided a synthetic and efficient explanation on how to adopt balanced nutrition, serving as a general guideline. Since then, there has been an enormous increase of researches related to confirmation of disease prevention through proper nutrition.

During the last years the Food and Agriculture Organization (FAO) together with Biodiversity International, pointed out the importance of "sustainable diets" that recognize the interdependence between food production and consumption, dietary requirements and nutritional recommendations, while at the same time confirming the concept that human beings' health cannot be disconnected from the health of ecosystems (FAO, 2010).

Despite these studies, public awareness seems to still lag well behind.

This is the first reason that leads the Barilla Center for Food \& Nutrition (BCFN) to the re-proposal of the food pyramid, 20 years after its conception. This elaboration of the food pyramid put forth by BCFN has been updated to carefully integrate the latest findings by research. The second reason involves global warming and, more in general, the impact of man's activities on the environment.

\section{Research Background and Results}

In recent years, confirmation regarding the importance of proper diet in preventing illness has increased enormously thanks to further laboratory studies and empirical evidence.

However, the same cannot be said about the public awareness, which has grown more slowly. This is the reason why, it was decided to offer once again the Food Pyramid, a familiar and well-established tool in the scientific and nutritional circles. The second reason is less obvious and is connected to the problem of climate change and, more generally, the impact of human activity on the environment (Wackernagel and Rees, 1996).

It has been demonstrated that agriculture and animal farming are among the sources that yield the greatest amounts of greenhouse gasses (beating out transportation) (Foster et al., 2006; Williams, Audsley, and Sanders, 2006). Therefore, as it's explicitly emphasized and suggested by the paper "Climate Smart Food" - drafted in November 2009 by SIK - the Swedish Institute for Food and Biotechnology, as charged by the mandate of the Presidency of the European Union hold by Sweden environmental variables must also be taken into account in regards to food and nutritional diet selection (Sonesson, Davis, and Ziegler, 2009). From this standpoint, the various food groups can be evaluated in terms of their environmental impact. 
The environmental indicators that have been selected to built BCFN Food Pyramid are: "(i) the Carbon Footprint, which represents greenhouse gas emissions responsible for climate change and is measured in terms of amount of $\mathrm{CO} 2$ equivalent; (ii) the Water Footprint (or virtual water content), which quantifies the amount of water resources consumed and how they are consumed; it measures water use in terms of volume and (iii) the Ecological Footprint, which measures the biologically productive land and sea area human activity requires to produce the resources it consumes and to absorb the waste it generates; it is measured in square meters or global hectares" (BCFN, 2010).

The use of the Life Cycle Assessment method places all environmental markers at the same level for the duration of the analysis: in this work, carbon, water and ecological footprint have been studied as key performance indicators of food production chains. The data came from available public studies (Ecoinvent Database; Environmental Product Declaration Database; LCA Food Database; Andersson, 2000; Baroni et al., 2006).

As stated in the BCFN publication (BCFN, 2010, p. 64): "the information is presented grouping foods according to the following categories that reflect the detailed process description: (i) foods derived from agriculture (fruit, vegetables, grains, etc.); (ii) foods derived from cultivation agricultural products (sugar, oil, pasta, etc.); (iii) foods derived from animal husbandry (dairy products, meat, etc.); (iv) foods from fishing; and (v) beverages. For every category examined, the values connected with each environmental indicator are given (...). The results for each of the environmental indicators examined (for both scientific studies and processed data) are expressed as a range of values since a specific value would not be representative of the category as a whole. For example, fruit includes a number of varieties with different cultivation processes and, as a result, a single value for the category "fruit" cannot be given for each indicator".

However, once results have been obtained, a need for both communicational conciseness and clarity imposes a simple method that accounts for all outcomes. This is why the ecological footprint served as base indicator in the construction of the double pyramid. All motivations shall be illustrated in the main BCFN paper, but it can be briefly stated that these essentially depend on the ability to easily convey the environmental impacts linked to food chains. Thereby, analysis of the food pyramid and its categories reveals a wide array of values concerning the environmental impact of each category in terms of Ecological Footprint (Ewing et al., 2010).

Thus, the reclassification of food goes beyond their positive impact on health, encompassing their impact on the environment, as well. These values are overlapped in descending order to obtain an upside-down pyramid that, in good measure, reproposes the same succession of foods. When this new Environmental Pyramid was brought alongside the Food Pyramid, it created a Food-Environmental Pyramid which called "Double Pyramid of Food and Environment" (BCFN, 2009, 2011, 2012).

It shows that those foods with higher recommended consumption levels are also those with lower environmental impact. Contrarily, those foods with lower recommended consumption levels are also those with higher environmental impact (Fig. 1). 


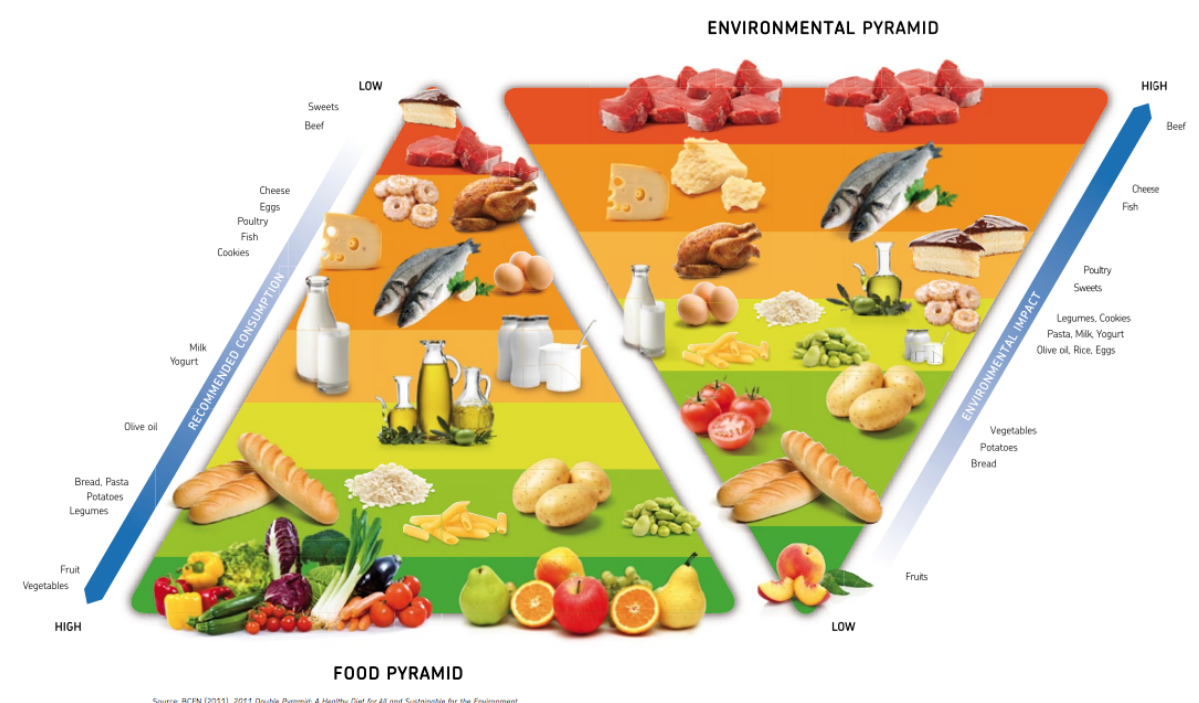

Fig. 1. The Double Pyramid of Food and Environment (Source: BCFN, 2012)

This newly-elaborated version illustrates, in a unified model, the connection between two different but highly-relevant goals: health and environmental protection. In other words, it shows that if the diet suggested in the traditional Food Pyramid is followed, not only do people live better (longer and healthier), but there is a decidedly lower impact - or better, footprint - left on the environment.

All of us, through eating responsibly, can definitely reconcile our personal wellbeing (personal ecology) with the environment (ecological context).

Applying the model to everyday life and in order to estimate the extent to which the food choices of individuals affect the environmental impact, in terms of Ecological Footprint, two different daily menus were analysed: both are balanced from a nutritional point of view, both in terms of calories and nutrients (proteins, fats and carbohydrates), but in the first one, the protein is of plant origin ("vegetarian menu"), while in the second, it is mainly of animal origin ("animal protein-based menu').

As it is shown in the figure 2, the animal protein-based menu has an environmental impact that is two and a half times higher than the vegetarian one: 41 square global meters compared to 15 ; that is, a difference of at least 26 , which represents a very significant share in the daily impact of an individual. The vegetarian menu has an environmental impact that is two and a half times lower than the meat one.

An additional analysis was based on the calculation of the features for four different weekly menus, all balanced from a nutritional point of view, but with the only difference that their source of protein is from animal or plant origin. The sustainable (or BCFN) menu includes both meat and fish, with a preference for white meat, and provides a balanced consumption of protein both vegetable or animal origin. The meat menu and the meat and fish menu provide more conspicuous 
consumption of protein of animal origin. Lastly, meat and fish are obviously excluded from the vegetarian menu, and the sources of protein are animal-based (cheese, eggs, etc.), as well as of plant origin (legumes).
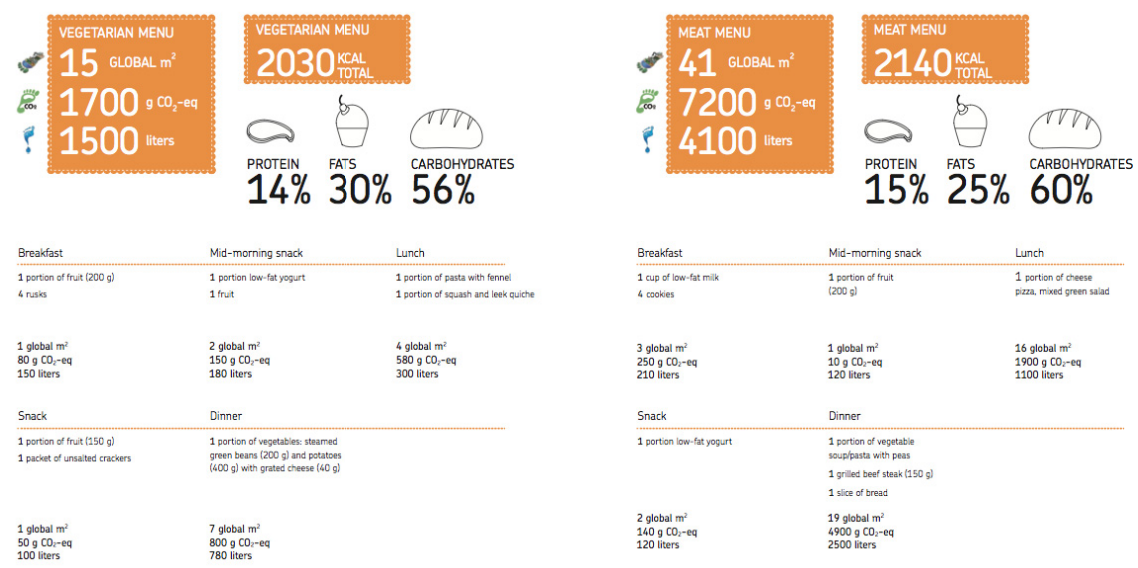

Fig. 2. Comparison between vegetarian and animal protein-based menu (Source: BCFN, 2012)

Regarding environmental impact, the two menus richest in meat and fish have values that are higher compared to the sustainable (BCFN) and to the vegetarian menu. In fact the sustainable and vegetarian menus have a Carbon Footprint respectively of 21 and $19 \mathrm{~kg} \mathrm{CO}_{2}$ eq. per week while the meat menu attains a Carbon Footprint of $32 \mathrm{~kg} \mathrm{CO}_{2}$ eq. per week (Fig. 3).

As it's shown in the figure 4, with a sustainable menu you can save up to 7,000 litre of water per week.

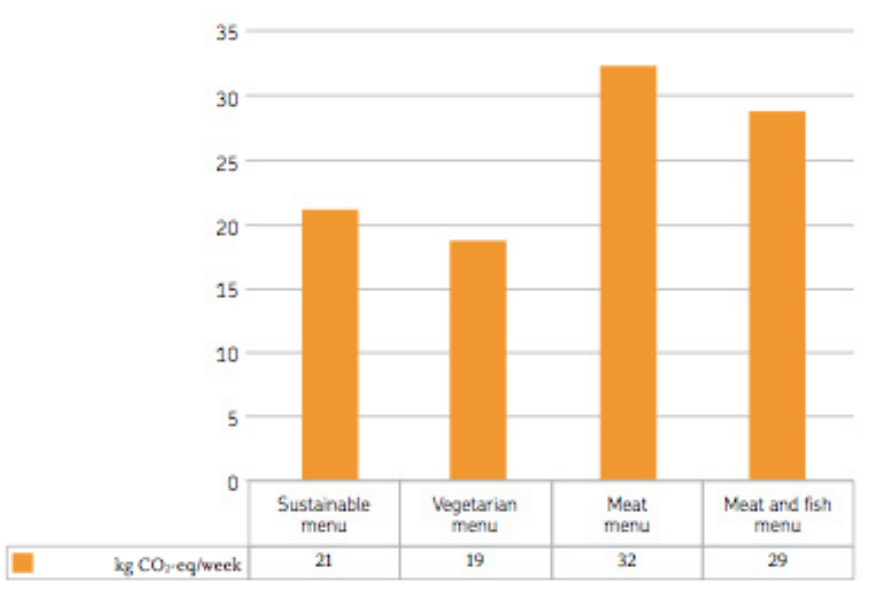

Fig. 3. Carbon footprint of the 4 menu analysed, all nutritionally balanced 


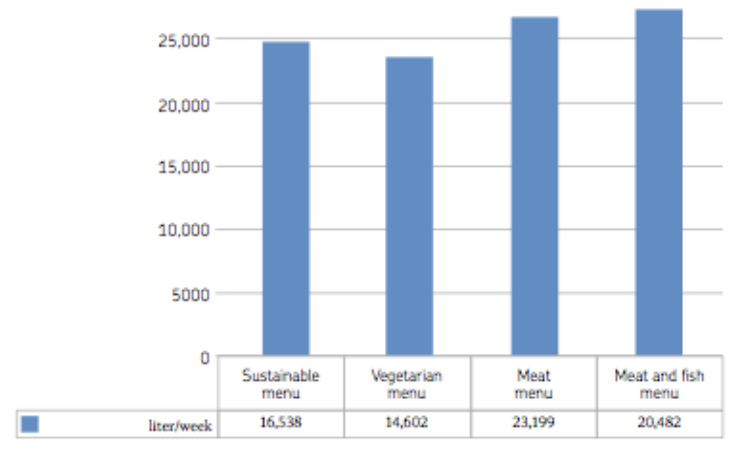

Fig. 4. Water footprint of the 4 menu analysed, all nutritionally balanced

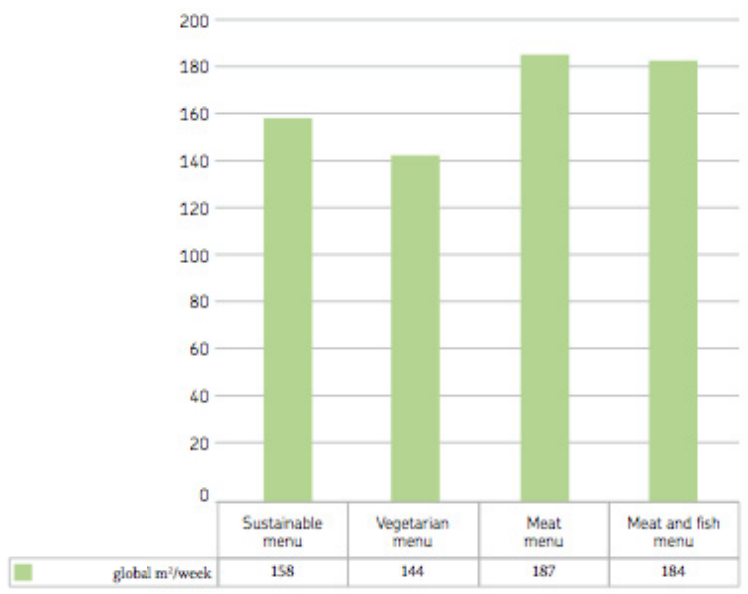

Fig. 5. Ecological footprint of the 4 menu analysed, all nutritionally balanced

To finish, if you chose a sustainable menu, you can have less environmental impacts also in term of ecological footprint (Fig. 4).

In the last version of the Double Pyramid publication (BCFN, 2012) it was pointed out the costs of sustainable diets, and in particular the Mediterranean one. The research question was: "Does sustainable diets cost more?".

As was used for the analysis of environmental subjects, public information sources are also used for this study. In this manner, the prices in Italy for typical diets are estimated, demonstrating that, when they have the same nutritional value, menus rich in protein of animal origin (meat and, especially, fish) have a slightly higher cost (about 10\% more). Comparing the outcomes with the results of other research studies conducted in other countries as United States, France, and Great Britain (USDA, 2012; Drewnowski et alt., 2005; Aggarwal, Monsivais, Drewnowski, 2012; Drewnowski, 2004; Drewnowski et alt., 2007; Cade, 1999; WWF, 2011), the situation does not appear to be the same. In fact, in some countries, the sustainable diet is more 
expensive for families, even if this fact can be at least partially conditioned by the different calculation criteria used (price per protein, price per gram, etc.).

Aside from some sectors for which additional analyses would be desirable, it may be affirmed in any case that the Mediterranean diet is the cheapest, as long as the foods are selected judiciously, preferring those which have a low cost and high nutritional value, such as pasta, legumes, certain types of vegetables, oil, and dried fruit. In particular, low-fat dairy products and eggs are the least expensive source of protein. The creation of a single-course meal based on vegetables enriched with a modest addition of meat may be the best method to provide the proper caloric and nutritional intake at a limited cost.

Therefore, sustainable eating definitely does not necessarily mean spending more money. However, this generally requires an additional effort by families in terms of the time dedicated to the selection and preparation of food.

\section{Conclusions}

The evidence of true interest that emerges from this new elaboration is the coincidence, in a single food model, of two different objectives that share fundamental importance for man: health and environmental protection. In other words, it has been demonstrated that following a diet put forward by the traditional food-nutrition pyramid not only leads to an improvement in quality of life (longer life-span and enhanced health conditions), but also yields a decisively lower impact, better expressed as Ecological Footprint, on the environment. Indeed, food that should be consumed in greater quantities, for example following the Mediterranean diet, fits into the category that inflicts less environmental impact overall. Vice-versa, foods falling into a recommendation of limited quantity consumption have also the higher impact on the environment. It has been demonstrated, that a vegetarian menu reduced by one third the environmental impacts compared to a animal protein-based menu.

The Double Pyramid model proposes the evaluation of all the choices and eating behaviours, even those which apparently, and at the present time, determine less obvious impacts on the individual or the community, but which can become substantial when measured cumulatively and over time.

With this in mind, the declination of the food and environmental pyramid regarding future generations, beginning with children, leads to some implications briefly mentioned below that can be further analysed and distributed to families and educators.

On the one hand, the dietary habits that are increasingly widespread among large sections of the population are leading to a gradual deterioration of the health of children and a consequent reduction in life expectancy, a fact which reverses an established trend of gradual improvement.

On the other hand, the excessive intake of certain foods - generally the same ones that should be eaten less frequently - determines a significant impact on the environment and the natural resources which, ultimately, can further reduce the quality of life and the overall well-being of future generations. 
Therefore, for its positive nutritional and environmental effects, the adoption of a correct food model impacts both directly and indirectly on the future of our children.

This makes it absolutely vital today to start a process of collective responsibility.

At this point, the BCFN's next focus is to promote actual implementation of the sustainable diet, by investigating potential obstacles, which would slow its spread or, in some cases, cause it to be abandoned by those who traditionally used it.

The first variable dealt with is that of price, rightly considered a potential obstacle, especially during the current economic crisis. The studies collected indicate that the situation is still debatable, although it would appear possible to state that the sustainable diet generally does not cost more, especially if its costs are evaluated using more appropriate criteria. The BCFN has found that the Mediterranean diet is, albeit slightly, more sustainable economically. And this cost comparison does not include the "hidden" costs of a poorly balanced diet, in terms of the environment and, especially, of people's health.

Certainly, much more research can be carried out on the topic of economic sustainability, especially if developing countries are included in the analysis (and it is indispensable that this be done) since, in these countries, the lack of resources and infrastructure, along with greater demographic growth, may render less economical that which is easily accessible in industrialized countries. How to make a sustainable diet truly accessible "to all" will be the subject of the BCFN's upcoming publications.

\section{References}

1. Aggarwal, A., Monsivais, P., Drewnowski, A.: Nutrient Intakes Linked to Better Health Outcomes Are Associated with Higher Diet Costs. In: The US. Open Access (2012)

2. Andersson, K.: LCA of Food Products and Production Systems. International Journal of LCA (4), 239-248 (2000)

3. Barilla Center for Food and Nutrition: Cambiamento Climatico, agricoltura e alimentazione (2009), http: / / www. barillacfn.com/uploads / file/62 / 1244800592_ClimateChangeIT_BarillaCFN_0609.pdf

4. Barilla Center for Food and Nutrition: Food and Health (2009), http: / /www.barillacfn.com/uploads/file/62/1252054022_Barilla CFN_FoodAndHealth.pdf

5. Barilla Center for Food and Nutrition: Double Pyramid: healthy food for people, sustainable for the planet (2011), http: / /www . barillacfn.com/paper / en_PositionPaper-BarillaCFN_DP.pdf

6. Baroni, L., et al.: Evaluating the environemntal impact of various dietary patterns combined with different food production systems. European Journal of Clinical Nutrition, $1-8$ (2006)

7. Burton, B.T., Foster, W.R., Hirsch, J., VanItallie, T.B.: Health implications of obesity: NIH consensus development conference. Internaitional Journal Obesity Related Metabolism Disorders 9, 155-169 (1985)

8. Cade, J., Upmeier, H., Calvert, C., Greenwood, D.: Costs of a healthy diet: analysis from the UK Women's Cohort Study. Public Health Nutrition 2(4), 505-512 (1999) 
9. Drewnowski, A., Monsivais, P., Maillot, M., Darmon, N.: Low-Energy-Density Diets Are Associated with Higher Diet Quality and Higher Diet Costs in French Adults. Journal of the American Dietetic Association 107, 1028-1032 (2007)

10. Drewnowski, A., Darmon, N.: The economics of obesity: Dietary energy density and energy cost. American Journal of Clinical Nutrition 82 (suppl.), S65-S73 (2005)

11. Drewnowski, A.: Obesity and the food environment: Dietary energy density and diet costs. American Journal of Preventive Medicine 27, 154-162 (2004)

12. Ecoinvent Database, http: / / www . ecoinvent.org

13. Environmental Product Declaration Database, http: / /www . environdec. com

14. Ewing, B., Moore, D., Goldfinger, S., Oursler, A., Reed, A., Wackernagel, M.: The Ecological Footprint Atlas 2010. Global Footprint Network, Oakland (2010)

15. FAO: Sustainable Diets and Biodiversity (2010)

16. Foster, C., Green, K., Bleda, M., Dewick, P., Evans, B., Flynn, A., Mylan, J.: Environmental Impacts of Food Production and Consumption: A report to the Department of the Environment, Food, and Rural Affairs. Manchester Business School. DEFRA, London (2006)

17. Keys, A., Aravanis, C., Blackburn, H.W., Van Buchem, F.S.P., Buzina, R., Djordjevic, B.S., Dontas, A.S., Fidanza, F., Karvonen, M.J., Kimura, N., Lekos, D., Monti, M., Puddu, V., Taylor, H.L.: Epidemiologic studies related to coronary heart disease: characteristics of men aged 40-59 in seven countries. Acta. Med. Scand. 460 (suppl.), 1-392 (1967)

18. Keys, A., Aravanis, C., et al.: Seven Countries. A Multivariate Analysis of Death and Coronary Heart Disease, pp. 1-381. Harvard University Press, Cambridge (1980)

19. LCA Food Database, http: / / www. LCAfood. dk

20. Must, A., Spadano, J., Coakley, E.H., Field, A.E., Colditz, G., Dietz, W.H.: The Disease Burden Associated With Overweight and Obesity. JAMA 282(16), 1523-1529 (1999)

21. Sonesson, U., Davis, J., Ziegler, F.: Food Production and Emission of Greenhouse Gases. SIK - the Swedish Institute for Food and Biotechnology (2009)

22. USDA: Are Healthy Foods Really More Expensive? It Depends on How You Measure the Price (2012)

23. Wackernagel, M., Rees, W.E.: Our ecological footprint: reducing human impact on the earth. New Society Publishers (1996)

24. Williams, A.G., Audsley, E., Sanders, D.L.: Determining the environmental burdens and resource use in the production of agricultural and horticultural commodities, Main Report, Defra Research project IS0205, Bedford: Cranfield University and Defra (2006), http: //www.silsoe.cranfield.ac.uk

25. WWF: Livewell: a balance of healthy and sustainable food choices (2011) 